Auckland University of Technology, Aotearoa New Zealand

2 School of Psychology, Massey University, Aotearoa New Zealand

\title{
"They feel like it's all based around the offender": Professionals explore how victim participation in family group conferences can be enhanced
}

\author{
Tracy Williams ${ }^{1}$ and Julia loane ${ }^{2}$
}

\begin{abstract}
INTRODUCTION: The Family Group Conference (FGC) is one of Aotearoa New Zealand's most innovative features to emerge in the Oranga Tamariki Act (1989). It was designed to address the harm caused by youth offending, as well as set the scene for reconciliation to allow victims to heal. However, victim participation at such conferences remains low.

METHODS: This study focused on a 6-month pilot project in 2019 between the agencies of New Zealand Police, Oranga Tamariki and Victim Support, that aimed to increase victim participation at FGCs within the Tāmaki Makaurau (Auckland) area. Rates of victim participation were tracked and six professionals were interviewed for their observations on the pilot.
\end{abstract}

FINDINGS: Victim participation in FGCs increased during the project and interviewees identified that there had been more collaborative efforts between the professionals involved. Thematic analysis highlighted issues with 1) Agency processes and systems (with more training and resources needed, and more streamlined processes between the three agencies called for); 2) Information (youth justice information and cases were "too complicated," and tended to be offender-focused, not necessarily understanding victim's perspectives nor getting feedback from them); and 3) Timing (improved processes were needed around timely police referrals and there were effects of timeframes overall on victim participation).

CONCLUSIONS: Participants recommended building on this exploratory pilot to increase and maintain better outcomes. The importance of victims being well-prepared for FGCs, feeling well-supported in making an in-person submission, in culturally appropriate ways, needs timely collaboration between well-trained and well-resourced professionals from the agencies involved.

KEYWORDS: Social work practice; Family Group Conference; youth justice; youth offending; process evaluation; Aotearoa New Zealand

Until the late 1970s, the criminal justice system globally was largely based on a retributive system, one that advocated for punishment (Strenlan et al., 2011). However, in response to the continued neglect of victims' needs and rights within such systems, "restorative justice" practices were introduced (Choi et al., 2012). These practices paved the way for addressing the "conflict and harm" associated with criminal 
behaviour by way of communicative and interactive practices known as "victimoffender conferences" (Bolitho, 2012). Restorative justice is seen as allowing victims the opportunity to get more of what they want from their criminal justice system (Strang et al., 2006), yet, when it comes to victims meeting their offenders through restorative processes, they are often reluctant to do so (Levine, 2000).

\section{The Family Group Conference}

In 1989, Aotearoa New Zealand was the first country in the world to develop the Family Group Conference (FGC) as a means to implement the values and principles of the Oranga Tamariki Act (1989). FGCs are used for the purposes of Youth Justicedelinquency and offending matters; and Care and Protection-to address the care and welfare needs of the child/young person. This study is exploring the Youth Justice FGC. The purpose of the Youth Justice FGC is to: a) hold the youth responsible by paying reparation to the victim and imposing a penalty; and $b$ ) explore the care and welfare of the young person (Levine, 2000). Convened by a Youth Justice Co-ordinator from Oranga Tamariki (OT), FGCs are decision-making meetings that include the young person and their family, the victim(s) and their (optional) support people, and a representative of police, to hear from all those involved (Morris \& Maxwell, 1998). A rehabilitative plan for the young person, followed up by the OT social worker, aims to help to keep young people out of the punitive justice system (Levine, 2000).

Subsequently, FGCs have been introduced elsewhere (e.g., the UK, Canada, Sweden, and the USA). Research into the effectiveness of FGCs remains largely positive, finding that: families are able to follow through with effective family plans that address the welfare concerns of the child who offended; are more likely to engage in the services recommended in the FGC; and give young offenders better contact with their extended family (Huntsman, 2006; Lowry, 1997;
Olson, 2009; Shore et al., 2002; Sundell \& Vinnerljung, 2004).

In Aotearoa New Zealand, young Māori and Pacific people are more likely to come to the attention of the youth justice system than Pākehā (NZ Europeans) (Maxwell et al., 2004). While early legislation allowed for decisions about youth offenders to be imposed with little or no involvement from families, this was not culturally appropriate according to traditional Māori or Pacific beliefs, which are largely based on collective responsibility (Ioane, 2017; Kaho, 2016). Hence, new legislation was built on restorative principles that are similar to the values that underpin Māori and many Pacific systems of justice. As a result, professionals need to strive to acknowledge and respect the cultural background of FGC participants to better meet the specific needs of the ethnic groups to which young offenders and their families belong (Kaho, 2016).

\section{Victim participation in FGCs}

A pioneering feature and therapeutic role of the FGC allows for the victim(s) of criminal offences to be present during the conference, an essential participation (Braithwaite \& Mugford, 1994) that sets the scene for reconciliation (Levine, 2000). Yet, victim attendance at youth justice FGCs in Aotearoa New Zealand remains low. In cases with a victim, only $35 \%$ of conferences had a victim present in 1992 (Thornton, 1993) and, prior to this, some studies revealed less than a quarter $(24 \%)$ included victim participation (Prchal, 1991). Non-attendance at conferences has been partly attributed to victims not being consulted about the time and place of the conference, nor being given enough notice (Levine, 2000). Victims reported their only form of support came from a police representative. This led to feelings of intimidation in front of offenders and their families, often leaving the victim feeling overwhelmed (Maxwell \& Morris, 1993).

In response to such criticism, as well as a lack of victim satisfaction and participation, 
the Act was amended in 1994, to apply bestpractice guidelines, yet more recent research (Slater et al., 2015) found that victims' level of timely involvement was still problematic. Victims who did take part were shown to benefit from the restorative FGC process (Mainwaring et al., 2019), especially when they could make an informed decision to actively participate, from the information provided, and were well-supported by those involved.

Levine and Wyn (1991) also suggested that careful FGC preparation is essential in order to establish effective victim involvement. Other issues reported include victims feeling daunted and overwhelmed when arriving at an FGC-often no-one is there to greet or support them as the co-ordinator is busy with the youth offender (Maxwell et al., 2004). Also, a key feature of an FGC is that youth offenders and their families should be able to express their views in a way that is constructive and restorative to the victim, and vice versa, in order for the healing process to eventuate. A great deal of practice and training is needed by the professionals involved to ensure all parties have an active voice in the process and the FGC is managed in a way that enhances participation (Maxwell et al., 2004).

Best-practice guidelines also need to include professionals' perspectives on how to ensure victim inclusion, according to Slater et al.'s (2015) study. While consultation between youth justice co-ordinators (who are employed by Oranga Tamariki) and Youth Aid officers (who are part of the police) has been described as the first and vital phase of any FGC, some of the attitudes of frontline police (who are supposed to refer offenders aged 17 and younger to Youth Aid) are believed to deter victim attendance (Slater et al., 2015). However, it is important to note that Slater et al.'s (2015) study was drawn only from the perspectives of youth justice co-ordinators; further research should also include the views of frontline police and other stakeholders. Co-ordinators reported a poor quality of accurate information from police at times, which not only impacted on their caseload, but also compromised their ability to meet timeframes set by the Act. Moreover, Police Summary of Facts ${ }^{1}$ sometimes contained inaccuracies that left participating victims feeling offended and unheard (Slater et al., 2015).

It would appear that the integrity of any FGC process is, to some extent, at the mercy of the involved professionals aligning their perspectives and their comprehension of the principles of the FGC Act (Slater et al., 2015), and that better processes might be needed between the various agencies and professional bodies involved in FGCs.

\section{Purpose of study}

In response to the Ministry of Justice "Youth Crime Action Plan 2013-2023" (Ministry of Justice, 2012), Tāmaki Makaurau (Auckland) police developed a local action plan in 2018 including a goal to improve FGCs. A pilot project aimed at increasing victim participation within FGCs, based on victim satisfaction studies and surveys (Ministry of Justice, 2018, 2019), started in March 2019 and ended in October 2019². The pilot was between New Zealand Police, Oranga Tamariki and Victim Support ${ }^{3}$ in Auckland, a collaborative effort between the three agencies to ensure an agreed understanding of procedures that would enable the FGC process to flow better. Instead of standard practice, where an FGC referral came from police to OT (who were responsible for contacting all participants to arrange the FGC), under the new pilot programme, the referral would still go to OT, but would also go to Victim Support (VS) who would be responsible for contacting the victim regarding the FGC. There was an initial presentation to introduce the pilot and a training session for staff on the new process of including VS in the referral chain.

This study is a process evaluation of the pilot project and was undertaken as part of Honours research. It is independent research aiming to explore the process 
by which a collaborative effort among agencies was undertaken which may lead to improvements in its future effectiveness (Patton, 2002), rather than focusing only on outcomes at the project's conclusion. Presser and Van Voorhis (2002) argued that there are few comprehensive evaluations of restorative justice interventions and yet the future possibilities of restorative justice are at the mercy of evaluation research. Moreover, they argue that evaluation research should focus more on the processes and less on the outcomes, to ensure results that are in harmony with restorative justice values.

The following research is an attempt to address this gap in the literature while keeping in mind the goal of enhancing victim participation at the FGC (Presser \& Van Voorhis, 2002). The four research questions were:

1. Was the pilot programme effective and how?

2. What could have been done better, or changed in the pilot programme?

3. Did the FGC referrals during the pilot programme result in increased victim attendance at FGCs?

4. What were the common modes of victim participation at the FGC?

It is intended that results from this study will assist the stakeholders / participants to develop guidelines for professional staff to benchmark, in order to enhance FGCs.

\section{Method}

The study used a mixed methods approach to gather rich and full data for the research questions (Regnault et al., 2018). Ethics approval was granted by Auckland University of Technology (19/156) and participants were sourced by emailing all members of VS, police and OT involved in the pilot project. The email contained information about the study and an invitation to participate. To allow for a collaborative random sampling process (Howitt \& Cramer, 2017), the first two participants from each organisation who accepted the invitation were selected as part of the random sampling approach and control of any biases (Howitt \& Cramer, 2017). The six chosen participants (about $12 \%$ of the workforce) were contacted by telephone to arrange a time for an interview at the workplace.

Qualitative data for this study were gathered in semi-structured interviews asking about the pilot programme's effectiveness, and what could have been done better, specifically relative to victim participation. Quantitative victim participation data were sourced from VS during the pilot. These data recorded the number of victims that were eligible to participate in FGCs during the pilot process but, to maintain confidentiality, did not incorporate any personal details. It was suggested that this would allow some pre- post-pilot comparison of victim participation (Howitt \& Cramer, 2017).

\section{Analysis}

Qualitative data were analysed using thematic analysis to develop themes that accurately reflected the textual data (Howitt \& Cramer, 2017) and were relevant to the research questions (Braun \& Clarke, 2006). A critical realist approach was adopted to understand the participants' experiences from their lived realities (Terry et al., 2017). In accordance with the critical realist worldview, the final themes were identified at a semantic surface level, as the researcher was interested in presenting what the participants reported during their interviews, rather than over-interpreting other possible "underlying" meanings (Braun \& Clarke, 2006).

A summary statistic was derived from the quantitative data to numerically measure the differences in victim participation prior to, and during, the pilot project (Balnaves \& Caputi, 2001; Howitt \& Cramer, 2017). 


\section{Results}

The sample included two professionals from each of three organisations (OT, police and VS) who had a wide range of time and experience (from 10 months to 22 years) in the youth justice sector; three were female; three were aged 31-45 and three were $46+$. As the youth justice field is so small, details of professional and ethnic identification are excluded to maintain confidentiality; participants are designated $P 1$ to $P 6$ in illustrative quotes.

All participants were aware of the purpose of the pilot project; that is, to support victims attending FGCs and increase participation from victims involved. As Participant 3, with 22 years' experience in youth justice, outlined, there was no doubt that the FGC could be a challenging concept for victims of offending:

There were times we had victims turn up to FGCs with "What the hell's going [on], why am I here? What is this kid front of me? You know, the guy who offended against me, why isn't he in prison?" All those sorts of questions will be going through the victim's mind. So, I'm guessing the pilot was probably designed to 1) make sure the victim understood the process; 2) get some input, and what that looks like; 3) probably understanding of the law, for some of them they probably don't understand that, you know, the punishments for adults and youths differ. (P3)

\section{Qualitative data analysis}

Following a robust thematic analysis of the transcribed interviews, three overarching themes (plus subthemes) were identified to respond to the four research questions. Theme 1 captures issues with agency processes and systems (including training needs of frontline staff and between agencies, the need for streamlined processes, and lack of resources). Theme 2 describes information issues (including that FGC processes seem too complicated, are overly offender-focused, sometimes not understanding the victim's point of view and value of feedback). Theme 3 gathers participants' views on timing (including timing of police referrals, the length of the pilot programme and other timeframes in general).

\section{Agency processes and systems}

This theme illustrated opinions about the need for transparent processes and systems across the agencies involved in FGCs, particularly around three subthemes of training, streamlining and resourcing.

\section{a) Training}

Participants felt more training with frontline police and between agencies was needed, so that the conference process could run smoothly. They identified a need for further initial training during the pilot project.

I think that there were some practical measures that weren't addressed in the initial process of starting up the pilot, and that needs to be addressed if it's going to succeed. (P2)

Consequently, they suggested training solutions, such as a refresher and ongoing contact:

Maybe a refresher training, bringing everyone back together ... just reminding everyone that this has been ongoing [the pilot]. Because I think we had the training and then there's probably not much talk about it after that. (P5)

\section{b) The need for streamlined processes}

A need for better processes was highlighted in order to help collaboration across organisations, so that referrals could flow better.

All organisations need to follow the other organisation's process and understand them... So that each organisation knows 
or puts in a process for themselves... Because there have been teething problems as we go along, we are trying to fix those teething problems, so that we know for next time how we can best provide a service. (P1)

For example, Participant 1 points out that using the contact service centre (at Victim Support) rather than emailing an individual staff member you may have happened to have dealt with before, was more efficient.

You go straight through to the contact service centre, don't email the person that's been working on either case in the past, you know, that you've dealt with in the past. Because then it gets confusing and gets more time-consuming...You try to advise them this is our process... So, it can run smoothly. (P1)

Participants pointed out that learning each other's roles and processes in the pilot took time and effort.

I think it's still really new, in the sense that we're all still working out the role of everybody and the process. So, I think it has the potential to be quite effective, but it's just still getting those working on, I guess, the baby steps to get there and just working out the process. (P5)

\section{c) Lack of resources}

Agencies need to have adequate resources for the additional training and streamlined processes to be implemented efficiently. As these participants point out, it was difficult to find time to complete pilot paperwork, in amongst all their other work and calls on their role.

Just being the only [person in this role] for this pilot, and it's coming hard and fast. And, you know, having to do the pilot, as well as other stuff ... I think that's the thing, is the resources, because there was a lack of resources. (P1)
Because what happens is just the sheer weight of paperwork that comes through, I've got it up there as my things to do and what I need to do, it's on my wall. But sometimes I forget to do it too. (P4)

\section{Information}

The second theme covers participants' insights on the information that had been acknowledged, uncovered, and shared within the pilot project. Subthemes highlighted the complexity of youth justice information and cases, the tendency to be offender-focused, not necessarily understanding the victim's perspective, nor getting feedback from them. These issues highlight the necessity for clearer information-sharing processes within the FGC system.

\section{a) It's too complicated}

This subtheme highlights participant accounts about how complicated youth justice can be, at times, for the professionals involved-let alone for victims.

So, it depends on what the crime is. For car conversions, for example, you know, there will be maybe six offenders. Most of the victims have no interest in going to an FGC, they just want reparation for their car, which is obviously not practical because the offenders are minors. The more serious ones, the sexual crimes and things, that's a little bit more complex.

There may be one offender with a number of victims, each of whom need a support worker and opportunity to participate, or cooffenders who have different youth justice co-ordinators for individual FGCs, making it "a lot to manage, without a really good system to keep it on track" (P5).

Which co-ordinator is dealing with which offender? ... we kind of get muddled up, you're doing one thing for one offender, for one victim, but there's more than 
one offender. ... It just needs to be a bit clearer. (P1)

The complexity can mean that the FGC is convened well after the offence has occurred, which can be problematic:

Because it's too complicated, we could retraumatise people contacting them late, they've moved on, because that [offence] has happened two months ago. (P2)

\section{b) Offender-focused}

Participants were concerned that, at times, FGCs appeared to be nothing more than tick-box approaches that were offenderfocused. There was some awareness of the implications of this for victims.

Because I think that the way some of the organisations involved, they just do it to tick boxes. And it's not purposely done, because for some victims, they feel like it's all based around the offender. (P1)

It's so hard for these victims of the FGCs anyway, because sometimes the victims are outnumbered by the offender's supporting family, or the youth supporting family. (P4)

\section{c) Perception of victim perspectives}

Within this subtheme, participants highlight their perception of victim perspectives and the importance of them being prepared for the FGC. These issues could also be perceived as an obstacle to an FGC being effective.

To me, we' ve sort of, in the past, we've had the victim, we've all gone about our business, thinking we're doing a good job, but not involving the victim enough, or not sort of making it clear as to why they're involved. (P3)

In contrast, when good support is provided for victims at FGCs, there is more opportunity to make the young offender understand the "face" of their offending.
I have seen or experienced good FGCs, where having the Victim Support worker there has been quite effective in terms of either supporting the victims, so they've got someone there, or having someone represent the victim. (P5)

I think it's just making the kid realise that, you know, that there's a face to this, there's a consequence, this is what's happened to this person ... yeah, it's much better when it's coming from that person. (P6)

Good victim support could also ensure language was not a barrier to a victim having a say, with Participant 6 being particularly impressed by a support person who was so well-prepared that the victim was able to speak in their own language, which was then translated. This allowed the victim to go into full details about the trauma they suffered at the hands of the offender.

\section{d) Feedback}

The last subtheme in this group outlines participants' thoughts about having more feedback from victims about FGCs.

I think any feedback ... whether it's negative or positive. You just got to take the good out of it, and if it's going to help the programme get better moving forward. ... Maybe at the end of the FGC when the kids finish their plan, and they get a discharge, that would be good to hear from the victim. As to "Okay, how do you think we did?" (P3)

\section{Timing}

The third theme describes the participants' narratives about timing within the pilot project, with improved processes needed around police referrals, and timeframes in general in FGCs.

\section{a) Timing of police referrals}

There was ongoing concern that a timely flow of referrals amongst agencies in the pilot did not seem to be improving: 
The whole process really relies on the frontline officers making the referral to Victim Support. ... So, given that we've been months into the pilot, those referrals are still, we' re still struggling ... like we' re still not getting details of the Victim Support worker or knowing that referral's actually been made. (P5)

\section{b) Length of the pilot}

A related issue was therefore whether the pilot project needed to be longer, to ensure systems really changed. Participants felt more time was needed in the project. Furthermore, the Christchurch Mosque shootings occurred in the middle of the initial project (although the pilot was in Auckland, extensive police resources from all regions were redeployed), which caused delays.

I think it needs a longer time period, the pilot needs to be a lot longer for it to be sustainable and to find some traction. ... It's too soon to say if, if any of it has worked. (P1)

I think that there have been a few hiccups along the way. Firstly, the timing that it started [the pilot project], was around the time that the Christchurch shootings happened. So, most police officers were busy with that. (P5)

\section{c) Timeframes in general}

Relating to the complex nature of youth justice cases (as in Theme 2: It's too complicated), participants commented on timeframes in general within FGCs that could compromise victim engagement. Participant 5 explains some of the time pressures arising from court requirements of timing and those who had to attend.

One of the other, I guess, challenges is our timeframes. When something comes from court, especially if the young person is in custody, we've got, you know, a week to organise the FGC and then a week to hold it. So, when that means adding in, or finding out who the [Victim] Support worker is, contacting them and adding on that extra person to the process, when we're already having to contact all the, like the police, the lawyers, the family, all these other people, it is a bit tricky. (P5)

\section{Quantitative data analysis}

Quantitative comparison data of victim participation at FGCs before and during the pilot project are illustrated in Figure 1, including the total number of victims entitled to participate in an FGC, how many chose to attend in person or to enter a submission, and how many chose not to participate. Prior to the pilot, the percentage of victims who participated, compared to the total entitled to participate, was low (January 2019, 50\%; February 2019, only 15.4\%).

During the pilot project, participation leapt to $100 \%$ (April, May, June 2019), and in July to October 2019, participation rates remained higher than pre-pilot. March 2019 can be seen as a transitional month, when the pilot had started, but was then interrupted by the Christchurch shootings, leaving overall attendance still relatively low that month $(29.7 \%)$.

Common modes of victim participation at the FGC moved from non-participation pre-pilot, to full participation during the pilot (where non-participation dropped to $0)$. The most common mode of participation was through providing a submission, rather than appearing in person, a pattern which continued from July to October 2019.

\section{Discussion}

This study was inspired by the current lack of comprehensive evaluations of restorative and youth justice interventions (Presser \& Van Voorhis, 2002). The aim of this study was to evaluate the process of a pilot project between New Zealand Police, Oranga Tamariki and Victim Support; the aim of the pilot was to increase victim participation 


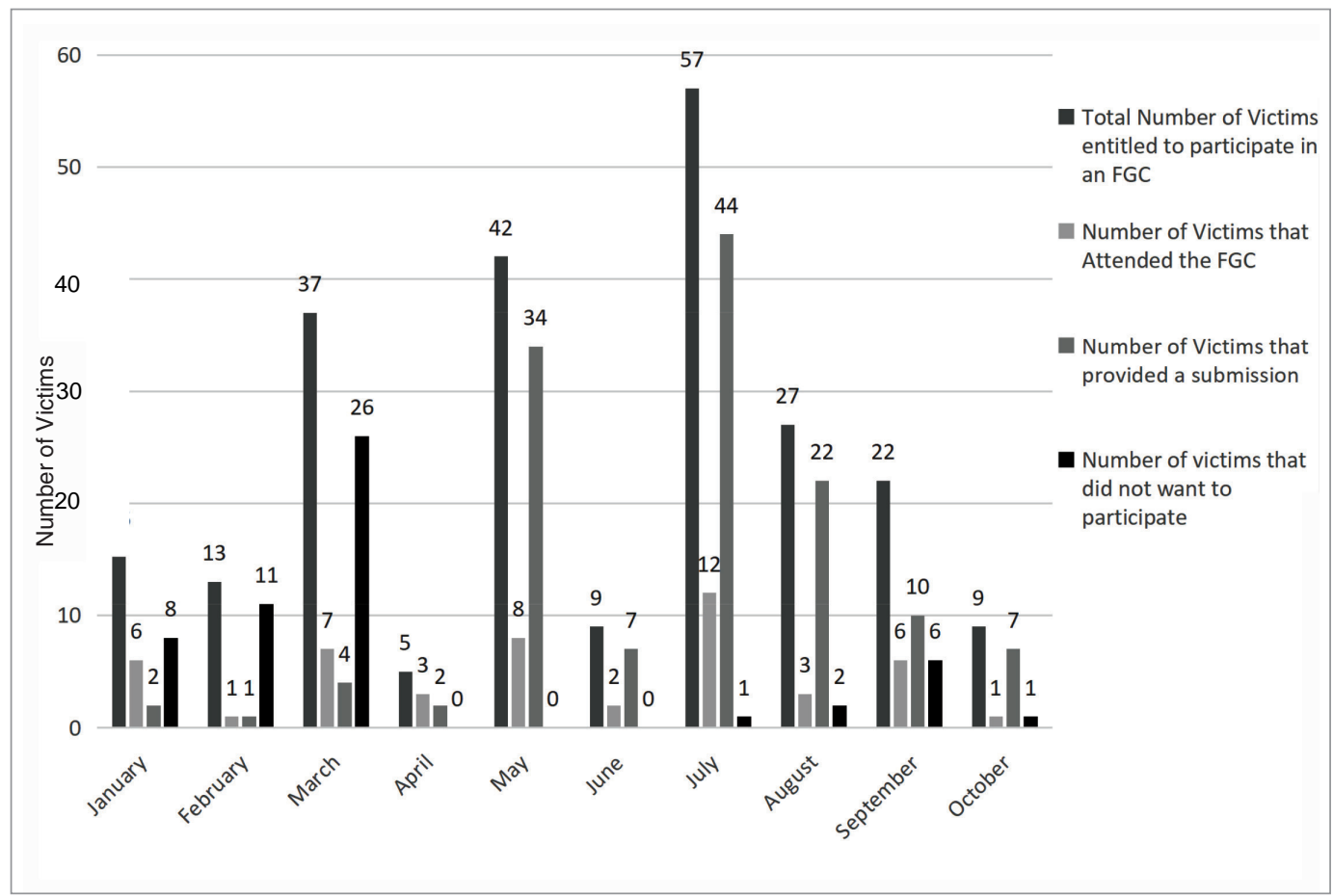

Figure 1. Victim Participation at FGCs (January-October 2019)

Note. January and February are prior to the pilot.

in FGCs in the Auckland area. It was hypothesised that a collaborative effort among these agencies would enable the conference process to flow better for victims. This section includes discussion of Research Question 1 and recommendations arising in response to Research Question 2.

\section{Research Question 1: Was the pilot project effective and how?}

Participants seemed to have a good understanding of the rationale for the pilot, suggesting a good grasp of current FGC challenges. They had a broad range and length of experience in the sector, highlighting the large amount of professional knowledge they possessed. When adding these together, the participants appeared to be the right fit to ensure a thoughtful exploration of the issues.

Efficacy of the pilot could be seen when the participants seemed to be generally aware of the importance of victims being well-prepared for conferences, even if it was not always possible to achieve that. This is also highlighted by Mainwaring et al. (2019), who found that victims need to understand the conference process, so that they can make an informed decision to attend and feel comfortable doing so. Similarly, Levine (2000) argued that lower rates of victim attendance at conferences could be partly due to the lack of preparation from the professionals involved. Further, professionals being able to describe the FGC process to victims, in a comfortable manner, provided an opportunity for restorative healing effects (Maxwell et al., 2004; Morris \& Maxwell, 1998). Our participants noted that cultural support for victims was vital, including ensuring that victims could speak or write in their own languages, with professional interpretation as required, which aligns with calls that cultural appropriateness should be implemented in international best-practice FGC guidelines (Brady, 2009). 
Another positive step in the pilot process was participants' awareness that FGCs could be seen as nothing more than tickbox approaches that are offender-focused, making them hard for victims. They realised that perhaps some organisations, or staff, needed to change their mindset, a change of heart that could eventuate in the victim feeling more comfortable to speak at conferences. This finding is also reinforced by Maxwell et al. (2004), who noted that victims frequently feel daunted and overwhelmed at conferences and need to feel that co-ordinators take a neutral and independent position, so that positive outcomes can be accomplished for all. Our participants' comments suggest they were aware of a need to be focused on collective outcomes at the FGC - that both offenders and victims benefit from the process-a focus that, when possible to achieve, was seen to be an effective attribute of the pilot project.

\section{Research Question 2: What could have been done better, or changed in the pilot programme?}

The findings from this question will be outlined as key recommendations.

\section{Recommendation 1: Intensive and enhanced training is required}

The research found that there was a need for more processes and systems within the pilot project (and, by implication, the FGC system overall), particularly around training. Firstly, more in-depth training was required during the initial start-up, with participants saying that better training preceding the pilot would have allowed for any practical measures to be revealed and addressed, ensuring that the pilot flowed better. This appears to be in line with Slater et al.'s (2015) findings that a successful FGC is based on having well-trained and skilled professionals to deliver good quality approaches at conferences.

\section{Recommendation 2: Targeted training for frontline police officers would help}

Participants were concerned about the amount of training for frontline police, who they felt needed more information regarding the pilot project, despite initially being spoken to by Youth Aid officers. This would ensure that other involved stakeholders could receive the correct information in the first instance, allowing the FGC process to flow better. This does not appear to be a new problem-Slater et al. (2015) also found that a lack of accurate information was handed on in referrals from police at times.

Participants also felt the training of frontline staff had an impact on the timing of referrals. While best-practice guidelines suggest that referrals should be made as early as possible, and prior to court decisions (Carruthers, 1997), findings in this study showed that referrals did not always come through in an appropriate timeframe, which left participants unable to fully prepare for the conference. As a result, referrals were delayed, timeframes were cut short, which added pressure when trying to contact victims in a timely manner-which in turn may compromise the quality of the conference, especially for victims (Slater et al., 2015). Perhaps this comes back to the role that Youth Aid officers play in the training of frontline staff, where the first and vital phase of any FGC is the consultation between co-ordinators and police Youth Aid officers (see also Slater et al., 2015), highlighting the important area of communication between professionals, and the need to enhance it.

\section{Recommendation 3: More streamlined processes within the FGC system are needed}

This would allow it to run more efficiently. Participants pointed out that there was a need to know each organisation's systems and processes better, which would allow collaboration to flow better. This is 
supported by previous research, when it was found that the efficacy of any FGC relies on the involved professionals aligning their perspectives (Slater et al., 2015). In addition, Case (2007) added that, when the views of professionals are not considered, it can be destructive to effective involvement for victims. The lack of streamlined processes affected the roles of some professionals within the pilot, only adding to their already large workload. Participants described feeling the added pressure that came from the pilot project and said that the extra workload that the pilot created greatly affected their active level of participation.

\section{Recommendation 4: Information systems need improvement}

Results also echoed some of the more familiar issues related to FGCs, according to the literature. There is a need for better information systems to cope with complicated areas of youth justice. The often high ratio of offenders to victims was noted by participants as placing an excessive volume of work on the professionals involved, with more resources needed. Complexity can affect timeframes in contacting victims, often leading to a higher risk of revictimisation (if a victim feels poorly prepared or unsupported in facing the offender), or simply a higher likelihood of victim non-attendance at the conference (Maxwell et al., 2004). Better information systems would allow for the easy identification of offender-to-victim ratio, as well as the correct parental information (where the victim is a minor) to be recorded. Consequently, this would save time for the stakeholders / professionals involved, as well as ensure that victims are fully supported, and so set the scene for reconciliation (Levine, 2000).

The quantitative data tracked victim participation, so Research Questions 3 (Did the FGC referrals result in victim participation at the FGC?) and 4 (What were the common modes of victim participation at the FGC?) really fit under the overall question of whether the pilot worked.

Research Question 3 showed that more victims were involved in FGCs during the pilot. As pointed out by Wundersitz and Hetzel (1996), when there is more effort focused on ensuring victims have equal priority to offenders when preparing for FGCs, victim attendance rates increase. Prior to the pilot project, victim participation numbers were as low as $15.4 \%$ and during the first month of getting the pilot project under way (March 2019), including teething problems, attendance was still relatively low at $29.7 \%$. Across the first three months of the pilot proper, participation increased to $100 \%$.

Participants wanted the pilot to be extended, partly due to the areas that required attention, and the impact on police due to the Christchurch Mosque shootings. Due to finish in June 2019, the pilot was extended through July and August and relatively good numbers of victim attendance were maintained (1 non-participant out of 57 victims in July; 2 out of 27 in August). Therefore, findings in this study show that victim participation at FGCs within the Auckland area increased during the pilot project and beyond.

Research Question 4 explored the modes of victim participation. Sometimes the serious nature of offences, such as violent or sexual assaults committed by youth (Maxwell et al., 2004), either prevents victims from attending at all, or discourages them from voicing their opinions when they do. This only highlights the importance of victims being able to enter submissions such as a victim impact statement, even if it is their sole mode of participation. There were more submissions provided by victims during and immediately following the pilot than before it. More victims chose to enter submissions as their only mode of attendance than did victims who decided to attend in person. This suggests that, in future, work could further explore the suggested gold standard 
of more victims participating in person, where feasible. While the literature suggests that personal attendance is warranted so that victims can express their feelings (Paul, 2016), and gain a level of emotional recovery that allows them to benefit from the restorative process (Strang et al., 2006), this is not always possible. Victims have the option to decline, though it would be helpful to explore the reasons for a submission only to ensure they are not due to systems and / or organisation barriers. Systemic and organisational barriers should be addressed to minimise further harm on a victim(s).

Nevertheless, the participants in this study suggest that the issues identified can be easily overcome. Some of the practical ways to implement the recommendations include: a) having more practitioners like Youth Aid officers who should be trained and involved right from the beginning, so that they can communicate with frontline police officers more often about the best ways to collaborate with Oranga Tamariki and Victim Support; b) holding regular refresher trainings for all involved, and presenting the findings from this study to help keep professionals on track. Bestpractice guidelines recommend training with professionals involved in FGCs should be ongoing (Carruthers, 1997); and c) Promote transparency among organisations so that they understand processes of their collaborative partners. Some participants were more optimistic about the implementation of more streamlined processes, claiming that, as soon as each organisation understands the other's processes, systems will then become more familiar, and timely collaboration could become "business as usual."

Participants echoed key recommendations found in international FGC research by Brady (2009) in Ireland, Carruthers (1997) in Canada, and Chandler and Giovannucci (2009) in the USA, including:

Stakeholder buy-in: Key stakeholders, such as the professionals who support offenders and victims, should be encouraged to participate and show commitment throughout an FGC programme.

Appropriate timing of referrals: Referrals should be made as early as possible, as well as prior to court decisions.

\section{Adequately trained and skilled professionals: Adequate and ongoing training should be provided to all professionals involved in the FGC process. Moreover, importance should be placed on the idea that facilitators are independent and remain impartial.}

Culturally appropriate processes: The FGC process should be conducted in a culturally appropriate manner and where possible, be in the same language as that mostly spoken by the participants.

Our pilot's participants endorsed these areas as important, with local solutions being enacted to varying degrees within the Tāmaki Makaurau pilot, as described by participants, that need to be continued and enhanced into FGCs nationwide.

\section{Limitations and future research}

The study's exploratory nature means that the results should be interpreted with caution; the qualitative sample was small and the quantitative detail limited to broad findings (of victim involvement, rather than detail of types of crimes and other factors that might affect that involvement). Future research could include more participants, including from management (e.g., regarding resourcing challenges) and victims who have been involved in FGCs (whether in person or by submission), and those who declined involvement. It may also be helpful to draw on the perspectives of the young person involved to contribute to a holistic and overall response so that the requirements of the FGC under the Act (1989), including the needs of the victim and the responsibilities of the young person, are appropriately explored. Additionally, a larger representative sample of participants 
that genuinely reflects the population groups most affected by FGCs will also be advantageous for future analysis and recommendations.

\section{Conclusion}

The barriers for victims that prevent them from participating in FGCs included agency processes and systems that were affected by lack of training and resources, information that was seen to be complicated and offender focused, and timing as an issue with police referrals and general timeframes. However, with the change in process to include Victim Support, the pilot project appeared to be effective in increasing the number of victims participating in FGCs, and in highlighting some of the barriers to participation. Further work is needed to increase the number of victims participating in person (rather than just by submission, or not at all), and in implementing recommendations for streamlined and timely processes of collaboration among professionals, who need to receive sufficient training and resources. It is our opinion that referring a matter to Victim Support from the outset of the process increases participation by victims, and therefore consideration should be made as to whether this process could continue. This will support positive steps towards the future of successful family group conferencing in Aotearoa New Zealand.

\section{Acknowledgements}

The authors wish to thank all the participants for their valuable insights and time in contributing to this research. We particularly acknowledge Victim Support for the opportunity to make this possible.

\section{Notes}

1 Defined as: A written, signed and witnessed statement produced by a victim, that is free from opinion, to be used in court.

2 The evaluation was initially scheduled for three months 1 March-1 June 2019. However, due to the terrorist attack in Christchurch on March 15, 2019, that necessitated immediate priority by police, it was decided that the pilot would be extended for a further three months, 1 March-1 September 2019.
3 Victim Support is a non-government organisation providing support, information and advocacy to people affected by crime and trauma. They act as an advocate for victims' rights and can help eligible victims apply to receive information about the person(s) who has caused them harm.

Accepted 14 May 2021

Published 1 September 2021

\section{References}

Balnaves, M., \& Caputi, P. (2001). Introduction to quantitative research methods: An investigative approach. Sage.

Bolitho, J. J. (2012). Restorative justice: The ideals and realities of conferencing for young people. Critical Criminology, 20(1), 61-78.

Brady, B. (2009). Barnardos Family Welfare Conference Service South Tipperary: Evaluation Report. UNESCO Child and Family Research Centre, National University of Ireland.

Braithwaite, J., \& Mugford, S. (1994). Conditions of successful reintegration ceremonies. Dealing with juvenile offenders. British Journal of Criminology, 34, 139-171.

Braun, V., \& Clarke, V. (2006). Using thematic analysis in psychology. Qualitative Research, 3(2), 77-101.

Carruthers, S. (1997). Mediation in child protection and the Nova Scotia experience. Family and Conciliation Courts Review, 35(1), 102-126.

Case, S. (2007). Questioning the evidence of risk that underpins evidence-led youth justice interventions. Youth Justice, 7(2), 91-105.

Chandler, S., \& Giovannucci, M. (2009). Family group conferences: Transforming traditional child welfare policy and pratice. Family Court Review, 42(2), 216-231.

Choi, J. J., Bazemore, G., \& Gilbert, M. J. (2012). Review of research on victims' experiences in restorative justice: Implications for youth justice. Children and Youth Services Review, 34, 35-42.

Howitt, D., \& Cramer, D. (2017). Research methods in psychology. Pearson Education.

Huntsman, L. (2006). Literature review: Family group conferencing in a child welfare context. Sydney Department of Community Services.

loane, J. (2017). Talanoa with Pasifika youth and their families. New Zealand Journal of Psychology, 46(3), 38-45.

Kaho, H. (2016). The family group conference: A Tongan perspective. New Zealand Law Review, 4, 687-721.

Levine, M. (2000). The family group conference in the New Zealand children, young persons, and their families act of 1989 (CYP\&F): Review and evaluation. Behavioural Sciences and the Law, 18, 517-556.

Levine, M. W., \& Wyn, H. (1991). Orders of the Youth Court and the work of Youth Justice Co-ordinators. Evaluation Unit, Department of Social Welfare.

Lowry, J. M. (1997). Family group conferences as a form of court approved alternative dispute resolution in child abuse and neglect cases. University of Michigan Journal of Law Reform, 31(1), 57-92. 
Mainwaring, C. J., Bardi, A., \& Meek, R. (2019). A glimpse into the role of personal values within the restorative justice process: A qualitative study with restorative justice facilitators. Contemporary Justice Review, 22(1), 60-85.

Maxwell, G. M., \& Morris, A. (1993). Family, victims, and culture. Social Policy Agency and Institute of Criminology. Victoria University of Wellington.

Maxwell, G. M., Kingi, V. M., Robertson, J. P., Morris, A., Cunningham, C., \& Lash, B. (2004). Achieving effective outcomes in youth justice. Ministry of Social Development.

Ministry of Justice. (2012). Youth crime action plan. https:// www.justice.govt.nz/justice-sector-policy/key-initiatives/ cross-government/youth-crime-action-plan/

Ministry of Justice. (2018). The New Zealand crime and victims survey. https://www.justice.govt.nz/justice-sectorpolicy/research-data/nzcvs/

Ministry of Justice. (2019). Strengthening the criminal justice system for victims survey. https://chiefvictimsadvisor. justice.govt.nz/assets/Documents/Publications/8dhfd3Criminal-Justice-Victims-Survey-report.pdf

Morris, A., \& Maxwell, G. (1998). Restorative justice in New Zealand: Family group conferences as a case study. Western Criminology Review, 1(1), 1-19.

Olson, K. B. (2009). Family group conferencing and child protection mediation: Essential tools for prioritizing family engagement in child welfare cases. Family Court Review, 47(1), 53-68.

Patton, M. Q. (2002). Qualitative research \& evaluation methods. Sage.

Paul, G. D. (2016). But does it work? The influence of presumed goal attainment effectiveness on willingness to use legalistic and restorative responses to offensive behaviour. Communication Studies, 67(2), 239-258.

Prchal, P. (1991). Profile of the first 50 youth justice referrals at Takapuna District Office. Social Work Review, 3, 12-13.

Presser, L., \& Van Voorhis, P. (2002). Values and evaluation: Assessing processes and outcomes of restorative justice programs. Crime and Delinquency, 48(1), 162-188.

Regnault, A., Willgoss, T., \& Barbic, S. (2018). Towards the use of mixed methods inquiry as best practice in health outcomes research. Journal of Patient-Reported Outcomes, 2(1), 19. https://doi.org/10.1186/s41687-0180043-8

Shore, N., Wirth, J., Cahn, K., Yancey, B., \& Gunderson, K. (2002). Long term and immediate outcomes of family group conferences in Washington State. International Institute for Restorative Practices.

Slater, C., Lambie, I., \& McDowell, H. (2015). Youth justice co-ordinators' perspectives on New Zealand's youth justice family group conference process. Journal of Social Work, 15(6), 621-643.

Strang, H., Sherman, L., Angel, C. M., Woods, D. J., Bennett, S., Newbury-Birch, D., \& Inkpen, N. (2006) Victim evaluations of face to face restorative justice conferences: A quasi-experimental analysis. Journal of Social Issues, 62(2), 281-306.

Strenlan, P., Feather, N. T., \& McKee, I. (2011). Retributive and inclusive justice goals and forgiveness: The influence of motivational values. Social Justice Research, 24, 126-142.

Sundell, K., \& Vinnerljung, B. (2004). Outcomes of family group conferencing in Sweden: A 3-year follow-up. Child Abuse and Neglect, 28, 267-287.

Terry, G., Hayfield, N., Clarke, V., \& Braun, V. (2017). Thematic analysis. In C. Willig, \& W. S. Rodgers (Eds.), The SAGE handbook of qualitative research in psychology (2nd ed., pp. 17-37). Sage.

Thornton, C. (1993). Family group conferences: A literature review. Practitioners Publishing.

Wundersitz, J., \& Hetzel, S. (1996). Family conferencing for young offenders: the South Australian experience. In J. Hudson, A. Morris, G. Maxwell, \& B. Galaway (Eds.), Family group conferences. Perspectives on policy \& practice (pp. 111-139). Willow Tree. 